\title{
Pre-, co-, and post- rockslide analysis with ALOS/PALSAR imagery: a case study of the Jiweishan rockslide, China
}

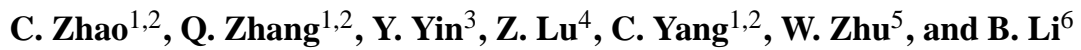 \\ ${ }^{1}$ College of Geology Engineering and Geomatics, Chang' an University, Xian, Shaanxi, 710054, China \\ ${ }^{2}$ Key Laboratory of Western China's Mineral Resources and Geological Engineering, Ministry of Education, No.126 Yanta \\ Road, Xian, Shaanxi, 710054, China \\ ${ }^{3}$ China Geological Survey, 45 Fuwai Dajie, Xicheng District, Beijing, 100037, China \\ ${ }^{4}$ Roy M. Huffington Department of Earth Sciences, Southern Methodist University, Dallas, Texas, USA \\ ${ }^{5}$ Department of Land Surveying and Geo-Informatics, Hong Kong Polytechnic University, Hong Kong, China \\ ${ }^{6}$ Institute of Geomechanics, Chinese Academy of Geological Sciences, South Road, Minzuxueyuan, Beijing, 100081, China
}

Correspondence to: C. Zhao (zhaochaoying@163.com)

Received: 14 April 2013 - Published in Nat. Hazards Earth Syst. Sci. Discuss.: 3 May 2013

Revised: 26 September 2013 - Accepted: 20 October 2013 - Published: 15 November 2013

\begin{abstract}
On 5 June 2009, a catastrophic rockslide debris flow occurred at the crest of the Jiweishan range, Chongqing Municipality, China, killing 74 people and injuring an additional eight. We use L-band ALOS/PALSAR imagery to address landslide processes before, during and after the slide. We employ three different SAR methods, i.e., short baseline subsets (SBAS) interferometric SAR (InSAR), SAR backscattering intensity change, and InSAR stacking algorithm, to study any ground deformation before the rockslide, investigate the affected area, and calculate the topographic change by this slide, respectively. First, continuous deformation has been observed based on the available ALOS/PALSAR InSAR imagery during June and December 2007. Second, the area affected by the landslide can be inferred based on changes in SAR backscattering intensity as well as surface topography, with an estimated area of 0.47 million $\mathrm{m}^{2}$. Last, an InSAR-derived post-slide digital elevation model has allowed us to estimate surface height changes due to the slide, reaching about $-80 \mathrm{~m}$ at the source region and about $60 \mathrm{~m}$ in the deposit region, respectively. Our InSAR-derived estimates have been validated using in situ data and 3-D lidar measurements.
\end{abstract}

\section{Introduction}

Rockslide is the movement of a mass of rock, debris, or earth down a slope under the influence of gravity (Cruden and Varnes, 1996). Rockslide failures have resulted in enormous casualties and huge economic losses in mountainous regions (Kwong et al., 2004; Parker et al., 2011; Xu et al., 2010). In recent years, many different mapping techniques have been implemented to study rockslide inventories, deformation monitoring, hazard, vulnerability assessments (Parise, 2001) and even post-event surface damage. In order to achieve the best results, both conventional methods such as geomorphological field mapping, visual interpretation of aerial photographs and new techniques such as interpretation and analysis of satellite imagery are frequently applied (Guzzetti et al., 2012).

Displacement monitoring of unstable slopes is a crucial tool for the prevention of hazards. It is often the only solution for the survey and the early warning of large landslides that cannot be stabilized or that may accelerate suddenly. Even for a historically occurred landslide, the pre-slide deformation recovery is too important not only for this landslide mechanism analysis, but also for any other similar landslides assessment and precaution.

The choice of an adequate monitoring system depends not only on the landslide type, size, and deformation rate, but also on the desired observation accuracy, frequency and 
even cost. Landslides monitoring techniques can be broadly subdivided in two main groups: geodetic and remote sensing techniques (Travelletti et al., 2012). Geodetic surveying methods, including levelling, theodolite, electromagnetic distance measurement (EDM) and global positioning system (GPS), are to measure the difference of height, angle, distance and even 3-D coordinates by repeatedly employing this equipment. High accuracy (around $0.2-2 \mathrm{~cm}$ ) can be desired, while the bench marks must be installed in advance and field works must be taken periodically. Another drawback of the geodetic method is that only discrete point measurements can be provided, which can hardly detect highly variable displacement rates in time and space of a landslide. On the other hand, remote sensing techniques operated from space-borne, airborne and ground-based platforms can provide larger coverage and denser point measurements than geodetic ones, which provide a good opportunity to monitor unstable areas and to assess surface height changes after landslides. Within remote sensing techniques, lidar (light detection and ranging) and SAR (synthetic aperture radar) are two prominent ones. Lidar (or laser scanning) provides highresolution point clouds of the topography. Deformation or surface height change can be deduced by differentiating two digital elevation models (DEMs) acquired at two different dates (Jaboyedoff et al, 2012). The absolute vertical accuracy of the lidar data, with respect to a standard geographic coordinate system, is $16 \mathrm{~cm}$ (Glenn et al., 2006). Four lidarderived Digital Terrain Models were studied over an active landslide at Montaguto (Italy) (Ventura et al., 2011). Interferometric SAR (InSAR) technique can generate DEM at $5 \mathrm{~m}$ accuracy when two SAR images have good spatial geometry and high coherence (Zebker et al., 1994; Zhao et al., $2012 b$ ). Otherwise, the accuracy will degrade to $12-15 \mathrm{~m}$ for unfavourable orbit latitudes and locations with large temporal decorrelation (Zebker et al., 1994). Accordingly, InSARdeduced DEM can measure topographic changes induced by a landslide (e.g. Lu et al., 2010). However, InSAR can monitor surface deformation in the line-of-sight (LOS) direction at the accuracy of $\mathrm{mm}$ to $\mathrm{cm}$ level, because the sensitivity of InSAR deformation is only related to the radar wavelength (Rosen et al., 2000; Massonnet and Feigl, 1998). Within the last two decades, the InSAR technique has been widely used in various landslide studies, not only for location detection (Cascini et al., 2010; Bulmer et al., 2006; Zhao et al., 2012a), but also for deformation monitoring. Various InSAR techniques have been employed, including the traditional differential InSAR method (Strozzi et al., 2005), the short baseline subsets (SBAS) InSAR method (Berardino et al., 2003), the corner reflector InSAR (Fu et al., 2010; Xia et al., 2004), the persistent scatterer InSAR technique (Hilley et al., 2004; Colesanti et al., 2003; Vladimir and Jan, 2011) and the ground-based InSAR technique (Leva et al., 2003). InSAR-derived landslide deformation patterns further provide insights into the dynamics of landslides, including the interaction of landslides and tectonic motions and the defor- mation characteristics in relation to the El Nino phenomenon (Hilley et al., 2004; Colesanti et al., 2003) and the precipitation rate (Zhao et al., 2012a). Besides the SAR phase measurement, SAR intensity information has been applied to infer the landslide-affected area (Lu et al., 2010) and to monitor large gradient deformation (e.g. Zhao et al., 2013). The challenges in the application of the InSAR technique to landslide investigation are mainly due to the vegetation and temporal decorrelation as well as atmospheric delay anomalies (Zebker and Villasenor, 1992; Berardino et al., 2003). Also, the side-looking SAR imaging geometry can cause layover and shadow defects in mountainous regions.

In reality, for the research of an historical landslide, the prerequisite is the data availability. Taking the example of Jiweishan rockslide, China, it occurred on 5 June 2009, so no any geodetic measurements, lidar or aerial photographs had been taken before the slide. And the rockslideinduced surface height change was measured by differentiating post-slide lidar-DEM and pre-slide coarse resolution DEM. Therefore, the archived SAR imagery data before and after rockslides can play unique roles for rockslide analysis during pre-, co-, and even post-slide stages. Our objectives for the Jiweishan rockslide are to (1) investigate surface deformation before the rockslide, (2) infer the affected area by the rockslide, and (3) estimate topography based on the rockslide.

\section{Jiweishan rockslide case study}

The Jiweishan rockslide debris flow occurred at the crest of the Jiweishan range, Chongqing Municipality, China, where an ore mine is located (Fig. 1). According to the classification of rockslides by Hungr et al. (2001), the Jiweishan rockslide can be classified as a rockslide debris flow. The Jiweishan range runs along the $\mathrm{N}-\mathrm{S}$ direction. The eastern flank of the range is a $50-150 \mathrm{~m}$ cliff facing Tiejiang creek to the east. The terrain over the Jiweishan varies from $1442 \mathrm{~m}$ a.s.l. at the peak to $1000 \mathrm{~m}$ a.s.l. at the foot, creating a height difference of about $440 \mathrm{~m}$. The rock movement can be traced back to the 1960 s, when a crack was found on the surface of the eastfacing cliff. In 1999, the width of the crack reached $1.5 \mathrm{~m}$ (Xu et al., 2010). In September 2001, some small-scale rockfalls occurred in the southern part of the cliff. After 2005, the rock fall activity increased and began to progressively extend to the northern part of the cliff. In July and August 2007, geo-hazard investigation of the Jiweishan was carried out by a professional geological team (Xu et al., 2010; Yin et al., 2011). A rock avalanche zone along the eastern cliff, about $1000 \mathrm{~m}$ long, $10 \mathrm{~m}$ wide, and $15-20 \mathrm{~m}$ high (a volume of about $200000 \mathrm{~m}^{3}$ ), was defined. The eastern boundary of the potential affected area (expectant rockslide risk zone shown in Fig. 1) is accompanied by Tiejiang creek at the foot of the mountain. People in the potential affected area were evacuated. However, at that time nobody predicted that such a large 
and high speed rockslide would occur in the Jiweishan, due to the limited understanding of the complex geomorphology and the historical activity of the slide. Unfortunately, at about 3:00 p.m. on 5 June 2009, after the instantaneous failure of the smaller front rock mass (resisting key block in Fig. 1), a rockslide was subsequently triggered. An approximately five-million cubic meter rock mass slid along the weak interlayer, in which coal, iron ore, or bauxite with about ten or more meters thick has been often excavated throughout the course of hundreds of years of mining (Yin et al., 2011). Driving blocks from the source area (the southern part of the Jiweishan) disintegrated quickly and dropped more than 50 $\mathrm{m}$ of debris into Tiejiang creek. Because of the huge kinetic energy, the sliding mass rode over the valley and ran up the opposite slope of Tiejiang creek. Blocked by this slope, the slide mass transformed into a high-speed debris flow, which travelled down along Tiejiang creek and formed a deposit about $2.2 \mathrm{~km}$ long (real rockslide hazard zone as shown in Fig. 1). An ore mine was obliterated, with a loss of 74 persons. It was estimated that the whole sliding process lasted less than $1 \mathrm{~min}$ (Xu et al., 2010).

To investigate this huge catastrophic rockslide avalanche (fragment flow), multiple methods including field investigation, remote sensing (except SAR imagery data), 3-D lidar and aerial photographs taken by an unmanned airplane were used (Xu et al., 2010; Yin et al., 2011). In this study, we employ satellite SAR imagery to recover the pre-slide time-series deformation, co-slide-affected area and post-slide height change. We arrange this manuscript as follows: Sect. 3 gives the SAR data and research schemes; Sect. 4 introduces the methods involved; Sect. 5 contains the results and analysis; and the last section provides some concluding remarks.

\section{Data set used in the analysis}

The Jiweishan mountainous region is located in the southwest of China, where the topographic relief is over $400 \mathrm{~m}$ (see Fig. 1). The foggy and rainy climate has made it impossible to obtain optical satellite imagery, and flourishing vegetation decorrelates InSAR imagery at shorter wavelengths. L-band Advanced Observing satellite (ALOS) Phased Array type L-band SAR (PALSAR) data has more advantages than C-band Envisat and X-band TerraSAR-X data due to its longer wavelength (e.g. Lu et al., 2010). Accordingly, we have obtained archived ALOS/PALSAR data over the study area: a total of 11 scenes of ALOS/PALSAR data are applied. A 3 arcsec SRTM DEM (http://srtm.csi.cgiar.org) is used for both differential InSAR deformation mapping and DEM change calculation. In order to get high-spatial deformation images, the fine-beam double polarization (FBD) images are oversampled to the pixel spacing of the fine-beam single polarization (FBS) images. Moreover, only a multilook number of 2 ( 1 pixel in the range and 2 pixels in the azimuth directions) is applied to generate InSAR interfero- grams at a spatial spacing of $\sim 7.5 \mathrm{~m}$ in both directions. Images at this spacing have the potential to detect small-scale rockslides and also are better suited to map rockslides with large deformation gradients at the expense of low coherence (Sandwell et al., 2008). Aiming to analyze the pre-, co-, and post- rockslide activities, 11 scenes of ALOS/PALSAR data are divided into the following 3 groups, which are shown in Fig. 2:

1. 7 interferograms before the 5 June 2009 rockslide are used to obtain pre-slide deformation time series;

2. 2 closest SAR intensity images spanning the 5 June 2009 rockslide are used to infer the area affected by the rockslide;

3. 7 interferometric pairs after the rockslide are used to obtain surface height change caused by the rockslide.

\section{Methodology}

Three SAR methods, the SBAS algorithm, SAR intensity change method and stacking interferograms, are applied in this research to analyze the pre-slide time-series deformation, co-slide-affected regions detection and post-slide height change analysis. The flow chart is outlined in Fig. 3.

\subsection{Pre-rockslide time-series deformation monitoring with SBAS algorithm}

In order to mitigate the atmospheric artefacts and the residual topographic effect in multi-temporal InSAR images, one of the advanced InSAR techniques termed as short baseline subsets (SBAS) InSAR technique is applied (Berardino et al., 2002). SBAS also works when limited interferometric sets are available (Mora et al., 2003). Before SBAS calculation, a minimum cost flow unwrapping algorithm (Chen and Zebker, 2002) is used to unwrap the phase in two dimensions and then a phase closure technique (Biggs et al., 2007) was used to identify the major unwrapping errors remaining in the interferograms.

For a given unwrapped interferogram $j$, the phase at pixel $(x, r)$ (where $x$ and $r$ are the azimuth and slant range coordinates, respectively) computed from the SAR acquisitions at epoch $t_{\mathrm{A}}$ (start time) and $t_{\mathrm{B}}$ (end time) can be written as follows (Berardino et al., 2002):

$$
\begin{gathered}
\delta \varphi_{j}(x, r)=\varphi\left(t_{\mathrm{B}}, x, r\right)-\varphi\left(t_{\mathrm{A}}, x, r\right)= \\
\delta \varphi_{j}^{\text {defo }}(x, r)+\delta \varphi_{j}^{\text {topo }}(x, r)+\delta \varphi_{j}^{\text {atm }} \\
(x, r)+\delta \varphi_{j}^{\text {noise }}(x, r),
\end{gathered}
$$

where $\delta \varphi_{j}^{\text {defo }}$ is slant deformation phase between $t_{\mathrm{A}}$ and $t_{\mathrm{B}}$; $\delta \varphi_{j}^{\text {topo }}$ represents topographic phase error, its impact on deformation maps is a function of the perpendicular baseline 


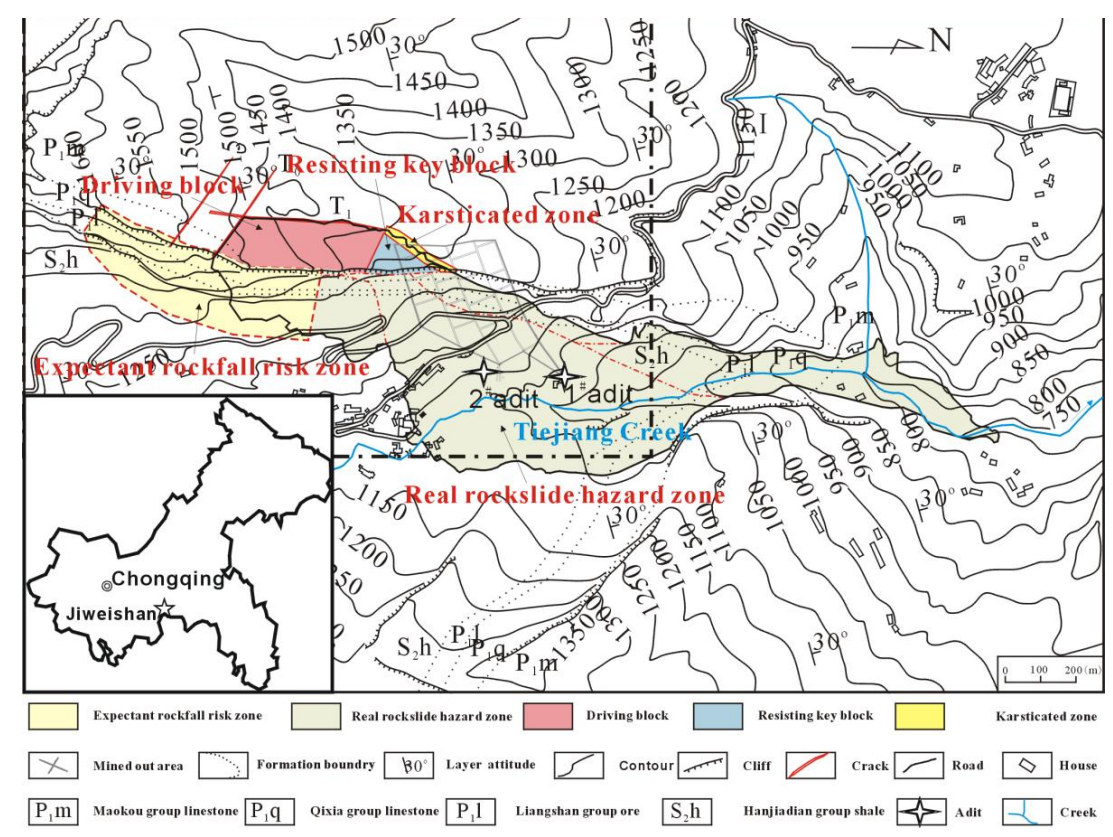

Fig. 1. Geomorphological map of the Jiweishan range, Chongqing Municipality, China. The Jiweishan rockslide is divided into a driving block and a resisting key block. Expectant rockfall risk zone and real rockslide hazard zone are superimposed. The SAR data cover the whole map and are used for co-slide and post-slide analyses as shown in Figs. 7 to 8, while the data cover up (left dashed rectangle) are used for pre-slide analyses as shown in Figs. 4 to 5. The inset is a sketch map of Chongqing Municipality, showing the relative location of the Jiweishan range.

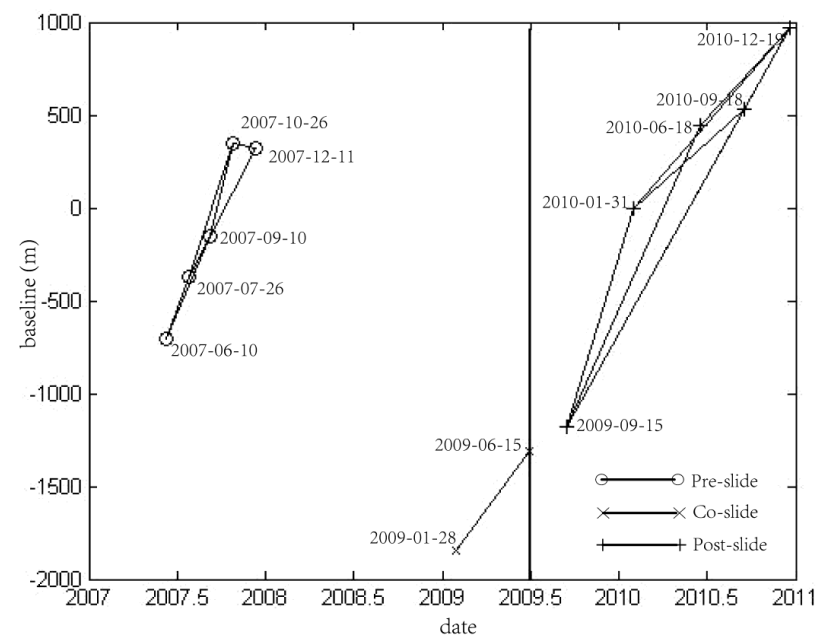

Fig. 2. Schematic figure on SAR combinations of ALOS/PALSAR imagery data for the Jiweishan rockslide analysis, different symbols indicate different SAR combinations.

$B_{\perp j}$, the slant range distance $R$, look angle $\theta$ and DEM error $\Delta Z ; \delta \varphi_{j}^{\text {atm }}$ accounts for temporal atmospheric variation at different SAR acquisition $t_{\mathrm{A}}$ and $t_{\mathrm{B}}$; the final term $\delta \varphi_{j}^{\text {noise }}$ is the other noise sum. The first three terms of the right side of Eq. (1) can be expressed as follows:

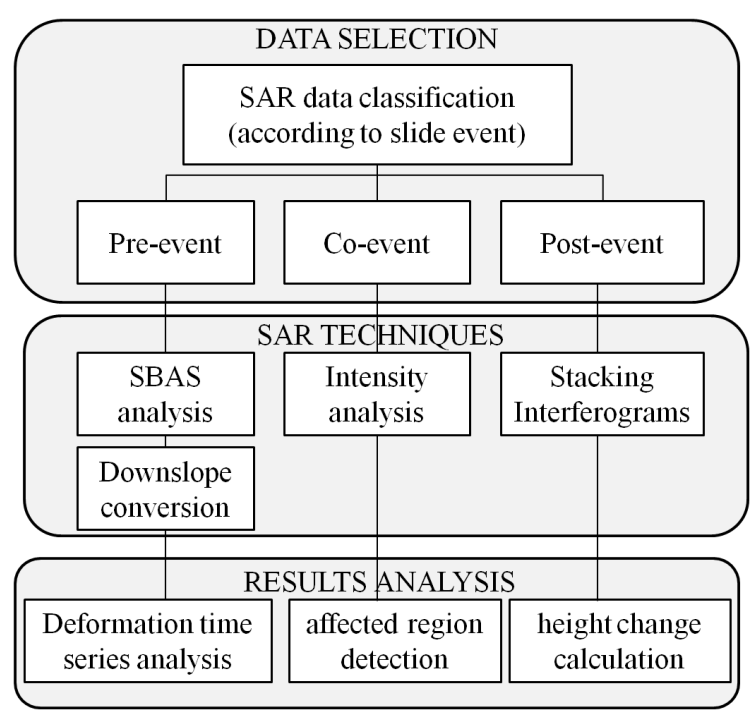

Fig. 3. The flow chart of SAR analysis for pre-, co-, and post-slide analysis.

$$
\left\{\begin{array}{l}
\delta \varphi_{j}^{\text {defo }}(x, r)=\frac{4 \pi}{\lambda}\left[d\left(t_{\mathrm{B}}, x, r\right)-d\left(t_{\mathrm{A}}, x, r\right)\right]=a_{\mathrm{j}}(x, r) \\
\cdot v+\delta \varphi_{j}^{\text {nl_defo }}(x, r) \\
\delta \varphi_{j}^{\text {topo }}(x, r)=\frac{4 \pi}{\lambda} \frac{\mathrm{B}_{\perp j} \Delta Z}{R \sin \theta}=b_{\mathrm{j}}(x, r) \cdot \Delta Z \\
\delta \varphi_{j}^{\text {attm }}(x, r)=\varphi_{\mathrm{atm}}\left(t_{\mathrm{B}}, x, r\right)-\varphi_{\mathrm{atm}}\left(t_{\mathrm{A}}, x, r\right)
\end{array}\right.
$$


where $\lambda$ is the SAR wavelength, $v$ is the deformation rate, $\delta \varphi_{j}^{\text {nl_defo }}(x, r)$ is the nonlinear deformation between two SAR acquisition dates. Eq. (1) can then be rewritten in matrix form as follows:

$\delta \varphi(x, r)=[A(x, r), B(x, r)]\left[\begin{array}{l}v \\ \Delta Z \\ \end{array}\right]+N(x, r)$,

where $A(x, r)=\left[a_{1}(x, r) \cdots a_{\mathrm{M}}(x, r)\right]^{T}, \mathrm{~B}(x, r)=$ $\left[b_{1}(x, r) \cdots b_{\mathrm{M}}(x, r)\right]^{T}$. The estimated linear deformation rate and DEM error phases are then subtracted from all unwrapped interferograms. Next, the atmospheric phase can be separated by high-pass filtering in the temporal domain and low-pass filtering in the spatial domain, because the atmospheric artefacts are spatially correlated and temporally random (Ferretti et al., 2001). If there exit several sub-data sets, a general inverse method such as singular value decomposition (SVD) is applied to estimate the deformation at each SAR acquisition date and DEM error. Then, the nonlinear deformation phase at different SAR acquisition dates will be calculated. Lastly, the accumulated deformation series can be achieved by integrating the deformation in each neighbouring SAR acquisition dates as follows:

$\delta \varphi_{k}^{\text {defo }}(x, r)=\left(t_{k}-t_{1}\right) v+\sum_{i=2}^{k} \phi_{i}^{\text {nl_defo }}$,

where $t_{1}$ is the earliest SAR acquisition date, $t_{k}$ is the $k$ th SAR acquisition date.

\subsection{Down-slope deformation calculation}

InSAR can only measure the deformation along the lineof-sight (LOS) direction. That is, the InSAR measurement represents the component of ground deformation projected to the LOS direction. Given some assumptions, the LOS deformation can be transformed to the measurement with a specific angle and azimuth direction. The transformation between the LOS direction and down-slope direction is straightforward. The unit vector of LOS can be defined as follows (Zhao et al., 2012a):

$\boldsymbol{r}=\left[\begin{array}{c}r_{\text {east }} \\ r_{\text {north }} \\ r_{\text {up }}\end{array}\right]=\left[\begin{array}{c}-\sin \theta \cos \alpha_{\mathrm{s}} \\ \sin \theta \sin \alpha_{\mathrm{s}} \\ \cos \theta\end{array}\right]$,

where $\theta$ is incidence angle with respect to the "flat earth", i.e. the angle between the vertical direction and the radar LOS, and $\alpha_{\mathrm{S}}$ is the satellite flight azimuth. The unit vector of slope direction can be defined as follows:

$\boldsymbol{u}=\left[\begin{array}{c}u_{\text {east }} \\ u_{\text {north }} \\ u_{\text {up }}\end{array}\right]=\left[\begin{array}{c}-\sin \alpha \cos \phi \\ -\cos \alpha \cos \phi \\ \sin \phi\end{array}\right]$,

where $\phi$ is the slope angle above the horizontal surface and $\alpha$ is the slope azimuth (aspect angle). So the deformation in the slope direction can be expressed as (Zhao et al., 2012a):

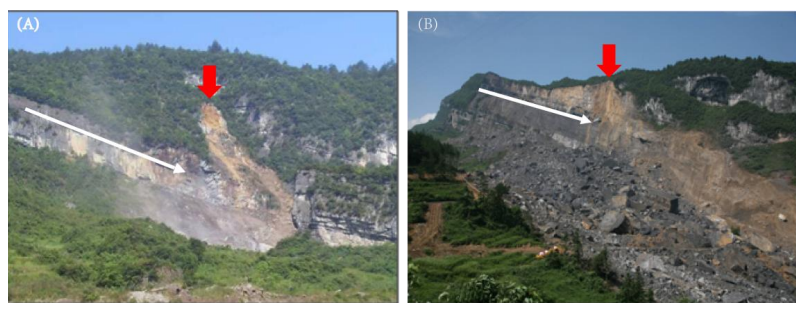

Fig. 4. Two photos over the Jiweishan rockslide, (a) taken $5 \mathrm{~h}$ before sliding and (b) taken after the sliding. Red arrows indicate the same location, while white arrows indicate the down-slope directions in different photos.

$d_{\text {slope }}=d_{\mathrm{LOS}} /\left(r_{\text {east }} u_{\text {east }}+r_{\text {north }} u_{\text {north }}+r_{\text {up }} u_{\text {up }}\right)$.

\subsection{Co-rockslide-affected region detection with SAR intensity map}

SAR backscattering intensity is the cumulative contribution of surface roughness, dielectric constant, and terrain slope, all of which are a function of radar parameters such as incidence angle, wavelength, and polarization (Ulaby et al., 1986). For the repeat-pass radar observations, the ratio of backscattering intensity qualitatively reflects the change in surface roughness and dielectric constant (which is primarily controlled by surface moisture) (Lu and Meyer, 2002; Lu et al., 2010). Therefore, we delineate the landslide-affected area mainly using the ratio of SAR backscattering returns. However, if the co-event SAR image pair maintains adequate coherence, the loss of coherence of the co-event interferogram can be used to further infer the area affected by the rockslide collapse (Lu et al., 2010).

\subsection{Post-rockslide height change calculation}

Before the rockslide on 5 June 2009, much of the Jiweishan was covered with heavy vegetation (Fig. 4a), resulting in a complete loss of coherence for C-band interferograms. The coherence for L-band interferograms is generally poor and can be lost if the perpendicular baseline is more than about $1 \mathrm{~km}$. However, after the sliding, the vegetation was destroyed (Fig. 4b), making the InSAR images coherent for a long time.

We employ the multi-interferogram method (Ferretti et al., 1999; Lu et al., 2003; Zhao et al., 2012b; Ebmeier et al., 2012) to generate a DEM that represents the surface topography after the rockslide. We produce interferograms with the shortest temporal intervals and mitigate the difficulty in phase unwrapping over the mountainous region by subtracting the 3-arc second SRTM DEM from each interferogram. Then the interferograms are stacked to calculate the final DEM change map. 


\section{Results and analysis}

\subsection{Pre-rockslide time-series deformation}

Firstly, SBAS-InSAR algorithm is applied to inverse the time-series surface deformation in line-of-sight (LOS) and its standard deviation before the Jiweishan rockslide. For the rockslide, the main deformation direction is in down-slope. Then InSAR-deduced time-series results and its accuracy are converted to down-slope direction. The flight direction of ascending ALOS satellite is $-10.2^{\circ}$ from the north and the incidence angle is $40.12^{\circ}$ from the vertical over the $\mathrm{Ji}$ weishan rockslide. The rockslide geometry is defined with the average azimuth direction as $12^{\circ}$ from the north and the average slope angle as $14.8^{\circ}$ below the surface (Xu et al., 2010). Accordingly, time-series deformation maps in downslope direction can be generated with the above-mentioned algorithm in Sects. 4.1 and 4.2. Four time-series deformation maps with a time separation of 46 days between adjacent acquisitions are shown in Fig. 5, in which both resisting key block and driving block of the Jiweishan slide are outlined. Lack of knowledge regarding the variations of slope and azimuth angles of Jiweishan landslide prevents us from applying spatially varied parameters. From Fig. 5, we can see the obvious deformation phenomena occurred as early as 10 June 2007 and the surface continuously deformed during the monitoring period. Unfortunately, we don't have earlier SAR data to trace the deformation before June 2007. Neither do we have coherent interferograms to allow us to analyze any ground deformation between 11 December 2007 and 5 June 2009. However, we are sure that precursory prerockslide time-series deformation exists based on the available interferograms (Fig. 5).

In order to closely analyze the InSAR deformation accuracy and the Jiweishan deformation characteristics before the slide, the cumulative deformation during 10 June 2007 and 11 December 2007 is shown in Fig. 6, where the resisting key block and driving block of the Jiweishan slide are outlined once more and the total deformation (in 184 days) along profile $A B$ is shown in Fig. 7. The error bar of deformation profile indicates the 1-sigma uncertainty in downslope direction. The lowest accuracy is $3 \mathrm{~cm}$, which occurred at fewer points, while most InSAR points have an accuracy better than $1 \mathrm{~cm}$. Moreover, the points located in stable areas and the maximum deformation area have an accuracy better than $0.5 \mathrm{~cm}$.

Based on Figs. 5 and 6, the driving block of the Jiweishan, the source of the 5 June 2009 debris flow, is obviously distinguishable from the stable part indicated by the gray bar in Fig. 7; the resisting key block has not been monitored for the sake of incoherence, which resulted from heavy vegetation and surface mass migration (see Fig. 4a). The length of the driving block is over $600 \mathrm{~m}$, while its average width is around $150 \mathrm{~m}$. The deformed geometry can be partially verified with an aerial photograph taken after sliding (shown as inset in
(1) $20070610-20070726$

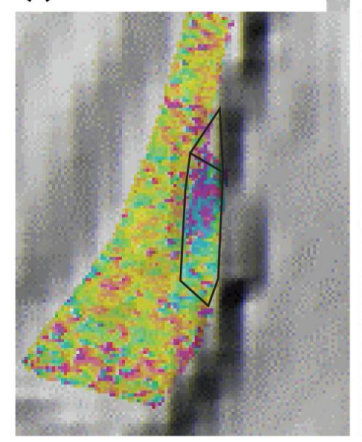

(2) 20070726 - 20070910

(3) $20070910-20071026$

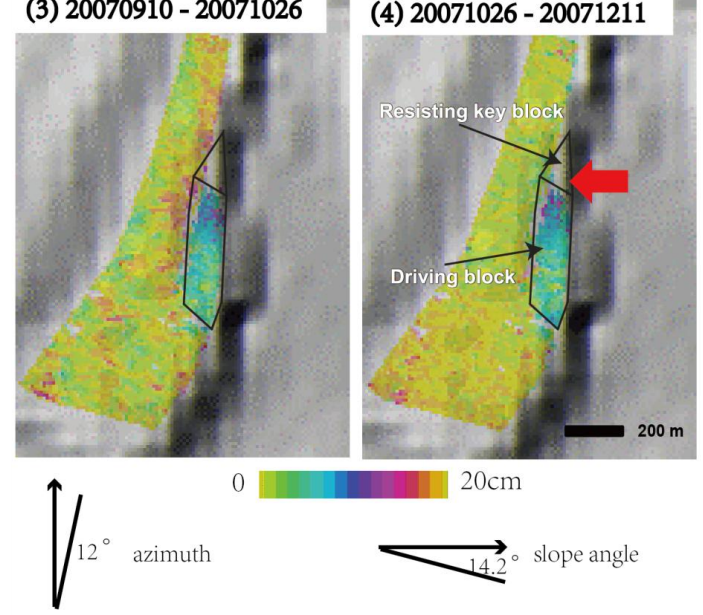

Fig. 5. Deformation maps within 46 days over the Jiweishan region before the 5 June 2009 slide, the red arrow indicates the same location as shown in Fig. 4. The slide geometry is shown at the bottom of the figure.

Fig. 6). As shown in Fig. 1, the source area of the rockslide is divided into two parts: a driving block to the south and a resisting key block to the north. The driving block is a quasiquadrilateral shape in plane with a length of $480 \mathrm{~m}$ and an average width of $140 \mathrm{~m}$, while the resisting key block is a triangle shape in plane, with a length of $240 \mathrm{~m}$ and an average width of $130 \mathrm{~m}$ (Xu et al., 2010; Yin et al., 2011). So, the pre-slide deformed shape from our InSAR measurement and the sliding shape from the post-slide aerial photo are highly consistent.

As shown from Fig. 7, the deformed length of the Jiweishan slide is over $600 \mathrm{~m}$ along the profile $\mathrm{AB}$ based on InSAR measurements. There is a difference of around $100 \mathrm{~m}$ in length between the InSAR and the aerial photograph measurements. This is because the resisting key block of the slide is incoherent and no useful deformation can be achieved based on InSAR phase measurements. In addition, InSAR measurements suggest spatially variable deformation patterns along the slide (Fig. 7). The lower elevation part of the slide deformed more than the higher elevation part. The 


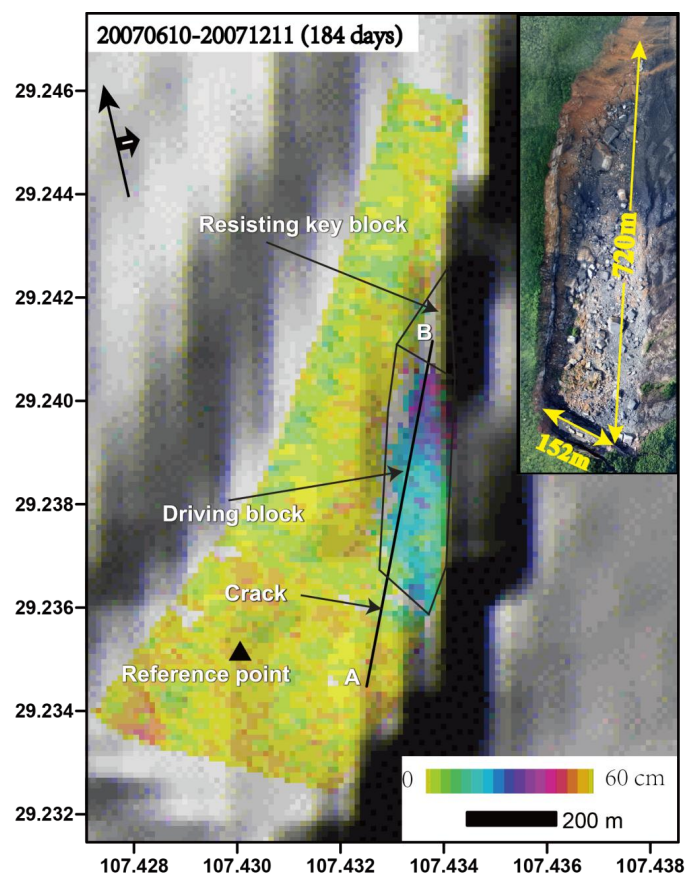

Fig. 6. The cumulative deformation map during 10 June and 11 December 2007 (184 days). Resisting key block, driving block and one of the back cracks of the Jiweishan slide are outlined. Black triangle indicates the reference point for InSAR time-series analysis. Profile $\mathrm{AB}$ will be discussed in Fig. 7. The inset is the aerial photograph taken after Jiweishan sliding (Yin et al., 2011).

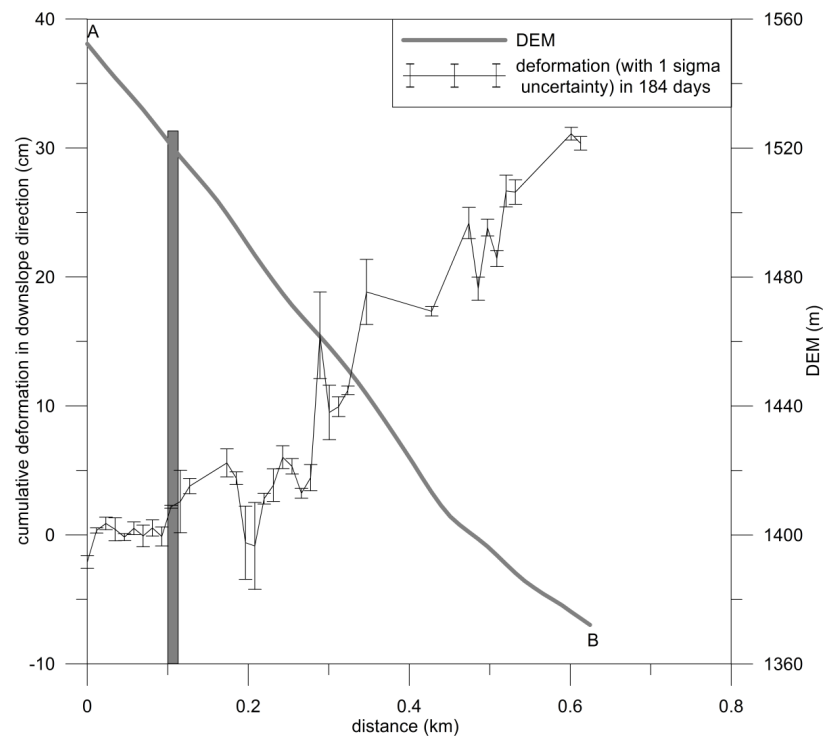

Fig. 7. Cumulative deformation in down-slope direction within 184 days and SRTM DEM along profile AB shown in Fig. 6. 1sigma uncertainty indicates the InSAR deformation accuracy in down-slope direction. The vertical grey bar indicates the back crack point (shown in Fig. 6).

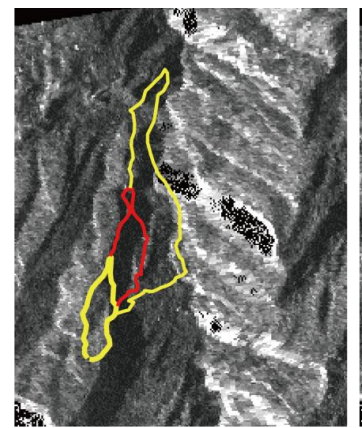

(a) intensity map in 20090128

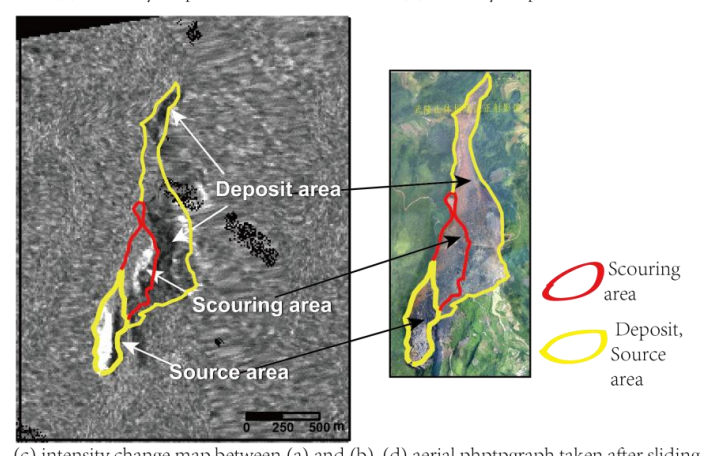

(c) intensity change map between (a) and (b) (d) aerial phptpgraph taken after sliding

Fig. 8. Two SAR Intensity images acquired on 28 January 2009 (a) and 15 June 2009 (b). (c) Intensity change map between (a) and (b). Dashed polygon is superimposed on each map onto indicate the affected area inferred from (d) aerial photograph taken after sliding. In (c) and (d), source area, scouring area and deposit area are all indicated.

maximum deformation within 184 days amounted to $30 \mathrm{~cm}$ in down-slope direction along this profile.

\subsection{2 Co-rockslide intensity change map}

Based on the archived SAR data, the two closest SAR images across the rockslide event are used to detect the affected area. The intensity maps acquired on 28 January 2009 and 15 June 2009 are shown in Fig. 8a and b, respectively, while the change map between Fig. 8a and b is shown in Fig. 8c. For comparison, the real rockslide hazard zone shown in Fig. 1 (Yin et al., 2011) is outlined with the dashed line and superimposed on each frame of Fig. 8. Areas with significant changes such as the source area, the scouring area and the deposit area, can be inferred based on SAR intensity changes (Fig. 8c), and the affected area is estimated as 0.47 million $\mathrm{m}^{2}$. The source and scouring areas are characterized by lower SAR backscattering returns after the sliding event, while the deposit area is marked with higher backscattering after the rockslide. However, we have found that SAR intensity images cannot delineate the whole area and source, scouring and deposit area affected by the rockslide as precisely as aerial photograph can (shown as Fig. 8d). If we had two SAR images with a shorter time span, we could also 
explore InSAR coherence change to assist the mapping of the affected area (Lu et al., 2010). Unfortunately, we do not have any adequate interferogram spanning the 5 June 2009 rockslide to allow us to infer the affected area based on coherence loss (Lu et al., 2010).

\subsection{Post-rockslide height change estimation}

In order to quantitatively assess the affected area and surface damage caused by the rockslide, a height change map (shown in Fig. 9) is generated based on the stacking result from 7 post-slide interferograms.

Firstly, as far as the affected area is concerned, it can be segmented into three parts (see Fig. 9): one source part to the south, the scouring area in the middle, and the deposit part to the north. The total length of the affected area is over $2 \mathrm{~km}$ and the maximum width of affected area is about $450 \mathrm{~m}$. Even though there are some incoherent areas caused by layover in the cliff and scouring regions, the height change map detected by InSAR is consistent with the thickness contour map measured by 3-D lidar technique (Yin et al., 2011) and is better than the result inferred from intensity change map (see Fig. 8). Because 7 interferograms are involved to calculate surface height change, while only two SAR images are used to delimitate the affected area. Secondly, in order to assess the surface height change calculated from InSAR data, lidar measurement is involved. Figure 10 shows the cross section of SRTM DEM, DEM change measured by InSAR and 3D lidar techniques.

From Fig. 10, we can conclude that the height and height change are reversely correlated, i.e., the mass slid from the higher elevation part to the lower elevation part. The length of source part is $600 \mathrm{~m}$, and the length of two deposit parts is $\sim 1.6 \mathrm{~km}$. The maximum decreased height was around $80 \mathrm{~m}$ over the source region and the thickest deposit was about $60 \mathrm{~m}$ located at the lower elevation part. The remaining debris entrained and scoured the convex slopes, crossed over Tiejiang creek, rushed up the opposite creek wall and was deposited at a lower elevation for another $\sim 30 \mathrm{~m}$. The DEM change profiles from InSAR and 3-D lidar measurements agree with each other very well. Quantitatively, the standard deviation of InSAR DEM change along the profile is around $8 \mathrm{~m}$ if the lidar DEM change measurement is assumed to be the reference. However, as mentioned before, the lidar survey was conducted only after the rockslide, so the accuracy of lidar DEM change estimation is also affected by the low accuracy of pre-slide SRTM DEM. The vertical accuracy of the pre-slide SRTM DEM is typically less than $12 \mathrm{~m}$ (Farr et al., 2007), so the realistic accuracy of our InSAR DEM change map is about $14.4 \mathrm{~m}$. It should be noted that the InSAR measurement is affected by decorrelation over steep slopes and scouring areas. Ideally this problem can be mitigated by InSAR imagery of the opposite viewing geometry. On the one hand, the accuracy of InSAR DEM change in low coherence areas, such as steep slopes and scouring areas, can be com-

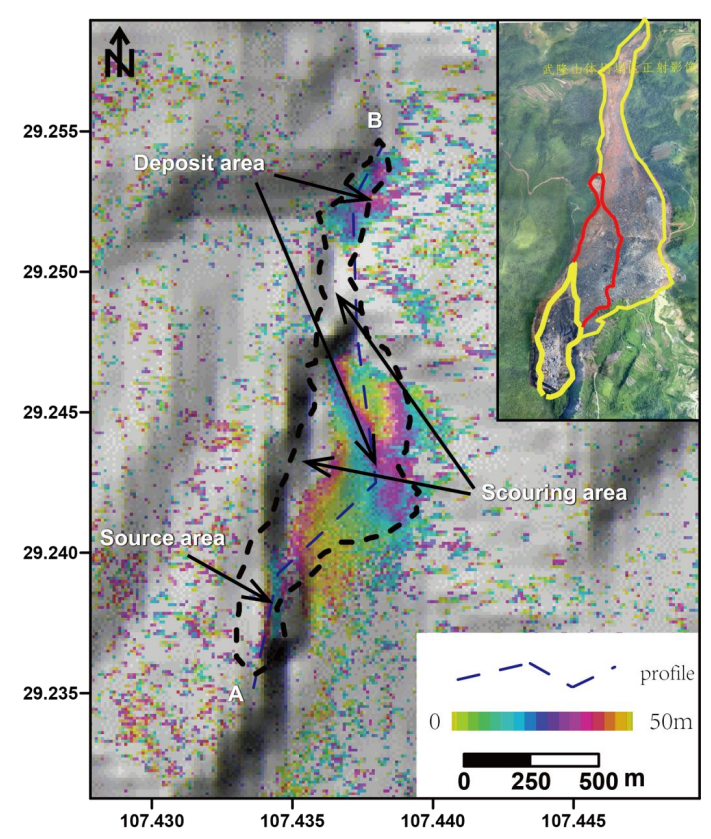

Fig. 9. DEM change map calculated by InSAR stacking method after Jiweishan sliding. The black dashed line delineates the affected region based on an aerial photo and the blue dashed line represents the location of the profile AB shown in Fig. 10.

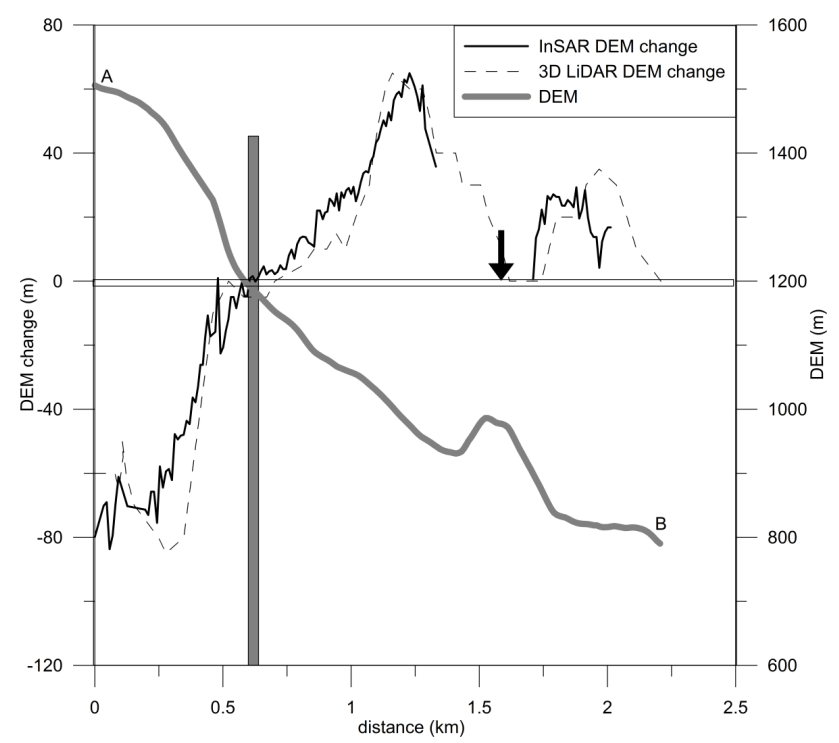

Fig. 10. Cross section of pre-slide SRTM DEM, DEM change measured by InSAR and 3-D lidar techniques after Jiweishan sliding along profile $\mathrm{AB}$. The vertical grey bar indicates the transaction point between the source area and the deposit area, while the black arrow shows the location of scouring area between two deposit areas.

pensated by opposite image geometries, so much void data can be avoided. On the other hand, the accuracy of InSAR DEM change in good coherence areas, can be significantly 
improved by averaging two independent DEM changes, i.e. the accuracy increase will be 1.4 times that generated from one single image geometry.

\section{Concluding remarks}

This research demonstrates the potential of archived SAR data to analyze the different stages of an historical rockslide, if no other geodetic and remote sensing data are available. With respect to the archived C-band Envisat/ASAR data, Lband ALOS/PALSAR data are selected due to their longer wavelength to keep high temporal and spatial correlations over vegetation-covered area, higher resolution and small multi-look number to monitor small rockslides in spatial domains and ascending track data rather than descending data to avoid the shadow of Jiweishan rockslide. In order to mitigate artefacts during the InSAR processing, SRTM DEM and ASTER GDEM are carefully compared in this mountainous region, and SRTM DEM is chosen due to its high performance in this region, atmospheric delay including tropospheric effect and ionospheric effect is also checked for each interferogram, and band-pass filtering is applied if required.

An InSAR procedure for an historical rockslide is proposed, and three InSAR (or SAR) methods are introduced for different rockslide stages research, including SBAS InSAR algorithm for pre-slide time-series deformation monitoring, SAR intensity change mapping for co-slide-affected area detection and stacking interferograms method for postslide height change measurement. Mostly, better than $1 \mathrm{~cm}$ standard deviation is achieved for pre-slide time-series deformation in down-slope direction, and $14.4 \mathrm{~m}$ accuracy of surface height change caused by rockslide is obtained by comparing with lidar measurements. Qualitatively, the co-slideaffected area and post-slide height change map are highly consistent with aerial photography and 3-D lidar measurements conducted after the rockslide. Moreover, rockslideaffected area estimated by post-slide stacking interferograms method is better than the SAR intensity change map and approximate 0.47 million $\mathrm{m}^{2}$ area was affected by this rockslide.

Most importantly, pre-slide time-series deformation has been recovered with limited available SAR imagery, which can be very useful to study the mechanism of this rockslide. Meanwhile, the proposed procedures for rockslide analysis with satellite SAR imagery over a remote, mountainous, heavily vegetated regions can be further extended to any other similar geo-hazards investigation and monitoring, which will be beneficial to slide early warnings and timely protection.

On the other hand, in most cases, if the ongoing deformation for a specific landslide (rockslide) is the point of interest, TerraSAR-X and COSMO/Skymed data are desired due to their high resolution, short wavelength and short revisit du- ration. If the landslide is covered by heavy vegetation, multitemporal lidar data are the best solution due to the small footprint of the laser and minimal penetration of the canopy at the optical wavelengths.

\section{Supplementary material related to this article is available online at http://www.nat-hazards-earth-syst-sci.net/13/2851/2013/ nhess-13-2851-2013-supplement.zip.}

Acknowledgements. ALOS/PALSAR data are copyrighted JAXA/METI and provided by the Alaska Satellite Facility through the ALOS Data Consortium. This research is funded by Natural Science Foundation of China (NSFC) (Grant No: 41372375, 41072266, 41274005, 41274004), National Program on Key Basic Research Project (973 Program) (Grant No. 2014CB744703) and the Ministry of Land and Resources, China (No: 1212011220142). Lastly the editor and two anonymous reviewers are appreciated for their many elaborative reviews and constructive suggestions.

Edited by: P. Tarolli

Reviewed by: two anonymous referees

\section{References}

Berardino, P., Fornaro, G., Lanari, R., and Sansosti, E.: A new algorithm for surface deformation monitoring based on small baseline differential SAR interferometry, IEEE Trans. Geosci. Remote Sens., 40, 2375-2383, 2002.

Berardino, P., Costantini, G., Franceschetti, G., Iodice, L., Pietranera, L., and Rizzo, V.: Use of differential SAR interferometry in monitoring and modeling large slope instability at Matera (Basilicata, Italy), Eng. Geol., 68, 31-51, 2003.

Biggs, J., Wright, T., Lu, Z., and Parsons, B.: Multi-interferogram method for measuring interseismic deformation: Denali Fault, Alaska, Geophys. J. Int., 170, 1165-1179, 2007.

Bulmer, M. H., Petley, D. N., Murphy, W., and Mantovani, F.: Detecting slope deformation using two-pass differential interferometry: Implications for landslide studies on Earth and other planetary bodies, J. Geophys. Res., 111, E06S16, doi:10.1029/2005JE002593, 2006.

Cascini, L., Fornaro, G., and Peduto, D.: Advanced low- and fullresolution DInSAR map generation for slow-moving landslide analysis at different scales, Eng. Geol., 112, 29-42, 2010.

Chen, C. W. and Zebker, H. A.: Phase unwrapping for large SAR interferograms: Statistical segmentation and generalized network models, IEEE Trans. Geosci. Remote Sens., 40, 1709-1719, 2002.

Colesanti, C., Ferretti, A., Prati, C., and Rocca, F.: Monitoring landslides and tectonic motions with the Permanent Scatterers Technique, Eng. Geol., 68, 3-14, 2003.

Cruden, D. M. and Varnes, D. J.: Landslide types and processes. Edited by: Turner, A.K., and Schuster, R.L., In: Rockslides, Investigation and Mitigation, Special Report 247, Transportation Research Board, Washington D.C., 36-75, 1996. 
Ebmeier, S. K., Biggs, J., Mather, T. A., Elliott, J. R., Wadge, G., and Amelung, F.: Measuring large topographic change with InSAR: Lava thicknesses, extrusion rate and subsidence rate at Santiaguito volcano, Guatemala, Earth Planet. Sc. Lett., 335, 216-225, 2012.

Farr, T., Rosen, P., Caro, E., Crippen, R., Duren, R., Hensley, S., Kobrick, M., Paller, M., Rodriguez, E., Roth, L., Seal, D., Shaffer, S., Shimada, J., Umland, J., Werner, M., Oskin, M., Burbank, D., and Alsdorf, D.: The Shuttle Radar Topography Mission, Rev. Geophys., 45, RG2004, doi:10.1029/2005RG000183, 2007.

Ferretti, A., Prati, C., and Rocca, F.: Multibaseline InSAR DEM reconstruction: The wavelet approach, IEEE Trans. Geosci. Remote Sensing, 37, 705-715, 1999.

Ferretti, A., Prati, C., and Rocca, F.: Permanent scatterers in SAR interferometry, IEEE Trans. Geosci. Remote Sens., 39, 8-20, 2001.

Fu, X., Guo, H., Tian, Q., and Guo, X.: Landslide monitoring by corner reflectors differential interferometry SAR, Int. J. Remote Sens., 31, 6387-6400. 2010.

Glenn, N., Streutker, D., Chadwick, J., Thackray, G., and Dorsch, S.: Analysis of LiDAR-derived topographic information for characterizing and differentiating landslide morphology and activity, Geomorphology, 73, 131-148, 2006.

Guzzetti, F., Mondini, A.C., Cardinali, M., Fiorucci, F., Santangelo, M, and Chang, K.T.: Landslide inventory maps: New tools for an old problem, Earth-Sci. Rev., 112, 42-66, 2012.

Hilley, G. E., Burgmann, R., Ferretti, A., Novali, F., and Rocca, F.: Dynamics of slow-moving landslides from permanent scatterer analysis, Science, 304, 1952-1955, 2004.

Hungr, O., Evens, S. G., Bovis, M. J., and Hutchinson, J. N.: A review of the classification of landslides of the flow type, Environ. Eng. Geosci., 7, 221-238, 2001.

Jaboyedoff, M., Oppikofer, T., Abellán, A., Derron, M., Loye, A., Metzger, R., and Pedrazzini, A.: Use of LIDAR in landslide investigations, a review, Nat. Hazards, 61, 5-28, 2012.

Kwong, A. K. L., Wang, M., Lee, C. F., and Law, K. T.: A review of landslide problems and mitigation measures in Chongqing and Hong Kong: similarities and differences, Eng. Geo., 76, 27-39, 2004.

Leva, D., Nico, G., Tarchi, D., Fortuny, G. J., and Sieber, A. J.: Temporal analysis of a landslide by means of a ground-based SAR interferometer, IEEE Trans. Geosci. Remote Sens., 41, 745-752, 2003.

Lu, Z. and Meyer, D.: Study of high SAR backscattering due to an increase of soil moisture over less vegetated area, its implication for characteristic of backscattering, Int. J. Remote Sens., 23, 1065-1076, 2002.

Lu, Z., Fielding, E., Patrick, M., and Trautwein, C.: Estimating Lava Volume by Precision Combination of Multiple Baseline Spaceborne and Airborne Interferometric Synthetic Aperture Radar: the 1997 Eruption of Okmok Volcano, Alaska, IEEE Trans. Geosci. Remote Sens., 41, 1428-1436, 2003.

Lu, Z., Dzurisin, D., Jung, H. S., Zhang, J. X., and Zhang, Y. H.: Radar Image and Data Fusion for Natural Hazards Characterization, International Journal of Image and Data Fusion, 1, 217-242, 2010.

Massonnet, D. and Feigl, K. L.: Radar interferometry and its application to changes in the Earth's surface, Rev. Geophys., 36, 441-500, 1998.
Mora, O., Mallorqui, J. J., and Broquetas, A.: Linear and Nonlinear Terrain Deformation Maps from a Reduced Set of Interferometric SAR Images, IEEE Trans. Geosci. Remote Sens., 41, 22432253, 2003.

Parise, M.: Landslide Mapping Techniques and Their Use in the Assessment of the Landslide Hazard, Physics and Chemistry of the Earth, Part C: Solar, Terrestrial and Planetary Science, 26, 697-703, 2001.

Parker, R. N., Densmore, A. L., Rosser, N. J., Marcello, de M., Li, Y., Huang R. Q., Whadcoat, S., and Petley, D. N.: Mass wasting triggered by the 2008 Wenchuan earthquake is greater than orogenic growth, Nat. Geosci., 4, 449-452, 2011.

Rosen, P., Hensley, S., Joughin, I., Li, K., Madsen, S., Rodriguez, E., and Goldstein. R.: Synthetic Aperture Radar Interferometry, Proc. IEEE, 88, 333-382, 2000.

Sandwell, D., Myer, D., Mellors, R., Masanobu, S., Benjamin, B., and James, F.: Accuracy and Resolution of ALOS Interferometry: Vector Deformation Maps of the Father's Day Intrusion at Kilauea, IEEE Trans. Geosci. Remote Sens., 46, 3524-3534, 2008.

Strozzi, T., Farina, P., Corsini, A., Ambrosi, C., Thüring, M., Zilger, J., Wiesmann, A., Wegmüller, U., and Werner, C.: Survey and monitoring of landslide displacements by means of L-band satellite SAR interferometry, Landslides, 2, 193-201, 2005.

Travelletti, J., Delacourt, C., Allemand, P., Malet, J.-P., Schmittbuhl, J., Toussaint, R., and Bastard, M.: Correlation of multitemporal ground-based optical images for landslide monitoring: Application, potential and limitations, ISPRS J. Photogrammetry, 70, 39-55, 2012.

Ulaby, F. T., Moore, R. K., and Fung, A. K.: Microwave Remote Sensing: Active and Passive, vol. III, From Theory to Applications, 1097 pp., Artech House, Norwood, Mass, 1986.

Ventura, G., Vilardo, G., Terranova, C., and Sessa, E.: Tracking and evolution of complex active landslides by multi-temporal airborne LiDAR data: The Montaguto landslide (Southern Italy), Remote Sens. Environ., 115, 3237-3248, 2011.

Vladimir, G. and Jan, V.: Monitoring of post-failure landslide deformation by the PS-InSAR technique at Lubietova in Central Slovakia, Environ. Earth Sci., doi:10.1007/s12665-011-0951-x, 2011.

Xia, Y., Kaufmann, H., and Guo, X. F.: Landslide monitoring in the Three Gorges area using D-INSAR and corner reflectors, Photogramm. Eng. Rem. S., 70, 1167-1172, 2004.

Xu, Q., Fan, X. M., Huang, R. Q., Yin, Y. P., Hou, S. S., Dong, X. J. and Tang, M. G., A catastrophic rockslide-debris flow in Wulong, Chongqing, China in 2009: background, characterization, and causes, Landslides, 7, 75-87, 2010.

Yin, Y. P., Sun, P., Zhang, M., and Li, B.: Mechanism on apparent dip sliding of oblique inclined bedding rockslide at Jiweishan, Chongqing, China, Landslides, 8, 49-65, 2011.

Zebker, H. and Villasenor, J.: Decorrelation in interferometric radar echoes, IEEE Trans. Geosci. Remote Sens., 30, 950-959, 1992.

Zebker, H., Werner, C., Rosen, P., and Hensley, S.: Accuracy of topographic maps derived from ERS-1 interferometric radar, IEEE Trans. Geosci. Remote Sens., 32, 823-836, 1994.

Zhao, C. Y., Lu, Z., and Zhang, Q.: Time-series deformation monitoring over mining regions with SAR intensity-based offset measurements, Remote Sens. Lett., 4, 436-445, 2013. 
Zhao, C. Y., Lu, Z., Zhang, Q., and de la Fuente, J.: Large-area landslides detection and monitoring with ALOS/PALSAR imagery data over Northern California and Southern Oregon, USA, Remote Sens. Environ., 124, 348-359, 2012a.
Zhao, C. Y., Qu, F. F., Zhang, Q., and Zhu, W.: A combined multiinterferogram algorithm for high resolution DEM reconstruction over deformed regions with TerraSAR-X data, J. Geodyn., 61, 148-153, 2012b. 